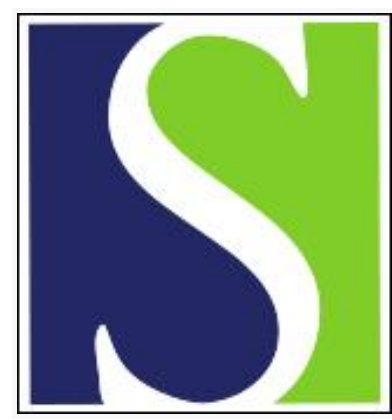

Scand J Work Environ Health 2021;47(7):483-487

https://doi.org/10.5271/sjweh.3984

Published online: 03 Sep 2021, Issue date: 01 Oct 2021

Understanding the impact of psychosocial working conditions on workers' health: we have come a long way, but are we there yet?

by Madsen IEH, Rugulies $R$

Affiliation: National Research Centre for the Working Environment, Copenhagen, Denmark. inm@nfa.dk

Refers to the following texts of the Journal: 2020;46(5):498-507

2020;46(3):231-234 2020;46(5):542-551 2021;47(7):489-508

2018;44(3):239-250 2017;43(1):50-58 2006;32(6):443-462

2006;32(6):431-442

The following article refers to this text: 2023;49(2):95-98

Key terms: editorial; exposure; psychosocial; psychosocial occupational epidemiology; psychosocial working condition; workers' health

This article in PubMed: www.ncbi.nlm.nih.gov/pubmed/34477882 


\section{Understanding the impact of psychosocial working conditions on workers' health: we have come a long way, but are we there yet?}

This issue of the journal includes a meta-review, ie, a systematic review of systematic reviews, summarizing the published evidence on the associations between exposure to adverse psychosocial working conditions and risk of developing diseases or disorders during the past 20 years (1). Although the authors allowed inclusion of reviews reporting results from cross-sectional studies, the majority of the included reviews were restricted to prospective cohort studies - the gold standard method in psychosocial occupational epidemiology. We commend the authors for their succinct summary of the current knowledge on the topic, encompassing this multitude of exposures and outcomes in one single paper. The paper finds that there is consistent evidence of associations between certain psychosocial working conditions (job strain, effort-reward imbalance, job insecurity, long working hours) and certain health conditions (cardiovascular diseases and mental disorders, in particular depression). The paper also identifies the lack of studies concerning numerous other working and health conditions, as elegantly depicted in their figure 1 , showing the presence or absence of reviews concerning all combinations of the included exposures and outcomes.

\section{The early days of psychosocial occupational epidemiology}

Compared to other fields of occupational health, research on psychosocial working conditions and health is a relatively recent discipline (2). One of the first studies on the topic was a paper by Friedman et al, published in 1958, reporting increased cholesterol levels and reduced blood clotting time among tax accountants during a period of putative high occupational stress, the annual April $15^{\text {th }}$ tax filing deadline in the United States (3). Curiously, though, this observation did not inspire research on occupational stressors but rather led to the development of the concept of "type A behavior", a behavioral pattern characterized by feelings of time urgency, competitiveness and hostility that became the dominant psychosocial explanation for risk of coronary heart disease in the late 1970s and early 1980s (4). The concept later largely disappeared from the discussion as findings from earlier epidemiological studies could not be replicated (5). In Belgium, Kornitzer and colleagues published a paper in 1975 on the risk of coronary heart disease in employees at two banks, and discussed whether the higher occurrence in one of the banks could be related to work organization (6), a hypothesis which they later examined and corroborated (7). In the 1960s in Sweden, Gardell, Frankenhaeuser and others pioneered both theoretical concepts and empirical research on the role of work under- and overload, participation and alienation for both workplace democracy and workers' health (8-10). This research inspired, among other things, the development of the demand-control model (job strain model) (11) that was tested in Swedish cohorts from the early 1980s (12, 13). The demand-control model quickly became the dominant approach for understanding the contribution of psychosocial working conditions to risk of cardiovascular disease, but reviews of these studies showed inconsistent results $(14,15)$. A major advance was made in 2012, when the "Individual-Participant Data Meta-Analysis in Working Populations (IPD-Work) Consortium published pooled estimates from 13 European cohort studies with almost 200000 participants, showing a prospective association between exposure to job strain and risk of coronary heart disease (16). A key novelty of the IPD approach was to apply harmonized measures of exposures and outcomes in all included cohorts. Subsequent papers from the IPD-Work consortium showed associations between job strain and stroke (17), diabetes (18) and depression (19), between long working hours and coronary heart disease and stroke (20), diabetes (21) and depression (22) and between effort-reward imbalance and coronary heart disease (23). 
Whereas research on psychosocial work environment and risk of cardiovascular disease has a long history, dating back to the 1980s, research on psychosocial work environment and mental disorders emerged only towards the end of the 1990s, but then rapidly accelerated. When Stansfeld \& Candy published the first systematic review and meta-analysis on psychosocial working conditions and common mental disorders in this journal in 2006, they identified only 11 papers (24). In contrast, a recent review by Mikkelsen et al identified 56 papers on the association between psychosocial working conditions and risk of incident clinical depressive disorders (25).

\section{The past 20 years of research}

The meta-review by Niedhammer et al only included reviews with meta-analyses that were published between 2000 and 2020. Given the acceleration of research and the growing number of studies published on the topic, this is a reasonable approach to provide an overview of the current knowledge base. Despite the restriction to the last 20 years, Niedhammer et al identified no less than 72 eligible review studies, a clear indicator of the massive proliferation of studies and the maturation of the research field.

Given this vast number of studies, it is timely to ponder what we have learned. For outcomes such as cardiovascular diseases and depression, the included reviews show rather consistently that employees who report certain psychosocial working conditions, in particular job strain, effort-reward imbalance, job insecurity and long working hours, are at increased risk. But how certain can we be that these associations are causal? First, caution is needed because most of the pooled estimates are modest, usually $<2.0$ and often $<1.5$. In the presence of numerous other well-established risk factors, such modest risk estimates make residual confounding a crucial issue. This discussion about causality is not new, and many arguments, such as those related to possible bias due to self-reported data, were raised decades ago $(26,27)$. Despite the massive research efforts, as evident by the number of studies published, it seems some disputes remain unchanged. For example, the above-mentioned recent review by Mikkelsen et al reported numerous associations between psychosocial working conditions and risk of depressive disorders (25), confirming and extending the results of the meta-review (1). However, due to methodological limitations of the literature, the authors did not feel confident to conclude whether psychosocial working conditions are likely or unlikely to cause depressive disorders.

\section{So what's next?}

So how can we move the research field of psychosocial working conditions and health forward? The discussion of causal inference, and how to arrive at it, is not limited to occupational health research. It is a topic of intense debate amongst epidemiologists and philosophers alike, and various approaches exist to establishing causality (28). While some have argued that applying well-defined hypotheses that correspond to potential interventions in combination with certain statistical methods and a counterfactual framework may lead to causal inference (29), others have argued that this approach is overly restrictive and risks limiting the topics that can be researched and the types of evidence that can be considered (30). The latter group proposes that causal claims are arrived at by piecing together bits of evidence from diverse studies, each with their own inherent strengths and weaknesses. Together these studies form a broader picture, like pieces of a puzzle, based on which we can form our judgement. Each study contributes only part of the whole and must be considered in light of the extant knowledge, with a keen eye on ruling out alternative hypotheses.

With this in mind, we propose that the identification of alternative hypotheses - in order to rule them out may be an important next step. Much criticism of psychosocial work environment research has focused on the role of potential biases related to the self-reported nature of exposure measurements in most studies on psychosocial working conditions and health, and calls have been made for studies measuring exposures objectively $(26,27)$. While the term objective may certainly also be debated (26), we and other research groups have been making steps to meet this challenge by applying non-self-reported exposure measures $(31,32)$, work unit aggregations $(33,34)$ or job exposure matrices to measure working conditions $(35-37)$. These measures also have their limita- 
tions. Job exposure matrices, for example, are vulnerable to non-differential misclassification, issues related to validation, and are unable to measure day-to-day or between-worker variation within the assigned occupational grouping (38). Consequently these studies should also be seen as only small pieces of the bigger puzzle. But within these limits, they may be considered small steps to rule out the alternative hypothesis of confounding due to reporting bias. Other small steps may be fixed-effects analyses examining intra-individual changes and thereby controlling for time-invariant confounders (39) or studies that analyze the association between onset of exposure and subsequent incident health outcomes (40). Alternative hypotheses may also pertain to the possibility of residual confounding due to factors such as personality, genetics, or life events outside the workplace (41-43). Ruling out these alternative hypotheses - and identifying more - could be considered important next steps for the research field.

The issue of causality is not only a technical and somewhat academic discussion. From the viewpoint of those many individuals who believe that they have acquired a health problem due to their psychosocial working conditions, the consequences of this rather academic discussion are very real. More evidence for a causal relationship could result in changes to compensation practices, which would make a tangible difference in the lives of these individuals. At the workplace and societal level, more certainty concerning causality could motivate preventive practices and possibly help prevent the potential adverse health consequences of psychosocial working conditions before they occur - a valuable goal for any public health professional, academic or not.

\section{Conflicts of interest}

The two authors are members of the IPD-Work Consortium and have been involved in several of the reviews that were included in the meta-review.

\section{References}

1. Niedhammer I, Bertrais S, Witt K. Psychosocial work exposures and health outcomes: a meta-review of 72 literature reviews with metaanalysis. Scand J Work Environ Health.2021;47(7):489-508. https://doi.org/10.5271/sjweh.3968

2. Gochfeld M. Chronologic history of occupational medicine. J Occup Environ Med. 2005;47(2):96-114. https://doi.org/10.1097/01 jom.0000152917.03649.0e

3. Friedman M, Rosenman RH, Carroll V. Changes in the serum cholesterol and blood clotting time in men subjected to cyclic variation of occupational stress. Circulation. 1958;17(5):852-861. https://doi.org/10.1161/01.CIR.17.5.852

4. The Review Panel on Coronary-Prone Behavior and Coronary Heart Disease. Coronary-prone behavior and coronary heart disease: a critical review. Circulation. 1981;63(6):1199-1215. https://doi.org/10.1161/01.CIR.63.6.1199

5. Myrtek M. Meta-analyses of prospective studies on coronary heart disease, type A personality, and hostility. Int J Cardiol. 2001;79(23):245-251. https://doi.org/10.1016/S0167-5273(01)00441-7

6. Kornitzer M, Thilly CH, Vanroux A, Balthazar E. Incidence of ischaemic heart disease in two cohorts of Belgian clerks. Br J Prev Soc Med. 1975;29(2):91-97. https://doi.org/10.1136/jech.29.2.91

7. Kittel F, Kornitzer M, Dramaik M. Coronary heart disease and job stress in two cohorts of bank clerks. Psychother Psychosom. 1980;34(2-3):110-123. https://doi.org/10.1159/000287453

8. Frankenhaeuser M, Gardell B. Underload and overload in working life: outline of a multidisciplinary approach. J Human Stress. 1976;2(3):35-46. https://doi.org/10.1080/0097840X.1976.9936068

9. Gardell B. Scandinavian research on stress in working life. Int J Health Serv. 1982;12(1):31-41. https://doi.org/10.2190/K3DH-0AXW7DCP-GPFM

10. Johnson JV, Gardell B, Johannson G, editors. The psychosocial work environment work organization, democratization, and health : Essays in memory of Bertil Gardell. Milton Park: Routledge; 1991.

11. Karasek R. Job demands, job decision latitude, and mental strain: Implications for job redesign. Administration Science Quarterly. 1979;24:285-307. https://doi.org/10.2307/2392498

12. Karasek R, Baker D, Marxer F, Ahlbom A, Theorell T. Job decision latitude, job demands, and cardiovascular disease: a prospective study of Swedish men. Am J Public Health. 1981;71(7):694-705. https://doi.org/10.2105/AJPH.71.7.694

13. Alfredsson L, Karasek R, Theorell T. Myocardial infarction risk and psychosocial work environment: an analysis of the male Swedish working force. Soc Sci Med. 1982;16(4):463-467. https://doi.org/10.1016/0277-9536(82)90054-5 
14. Kivimäki M, Virtanen M, Elovainio M, Kouvonen A, Väänänen A, Vahtera J. Work stress in the etiology of coronary heart disease--a meta-analysis. Scand J Work Environ Health. 2006;32(6):431-442. https://doi.org/10.5271/sjweh.1049

15. Eller NH, Netterstrøm B, Gyntelberg F, Kristensen TS, Nielsen F, Steptoe A, et al. Work-related psychosocial factors and the development of ischemic heart disease: a systematic review. Cardiol Rev. 2009;17(2):83-97. https://doi.org/10.1097/ CRD.0b013e318198c8e9

16. Kivimäki M, Nyberg ST, Batty GD, Fransson EI, Heikkilä K, Alfredsson L, et al. Job strain as a risk factor for coronary heart disease: a collaborative meta-analysis of individual participant data. Lancet. 2012;380(9852):1491-1497. https://doi.org/10.1016/S01406736(12)60994-5

17. Fransson EI, Nyberg ST, Heikkilä K, Alfredsson L, Bjorner JB, Borritz M, et al. Job strain and the risk of stroke: an individual-participant data meta-analysis. Stroke. 2015;46(2):557-559. https://doi.org/10.1161/STROKEAHA.114.008019

18. Nyberg ST, Fransson EI, Heikkilä K, Ahola K, Alfredsson L, Bjorner JB, et al. Job strain as a risk factor for type 2 diabetes: a pooled analysis of 124,808 men and women. Diabetes Care. 2014;37(8):2268-2275. https://doi.org/10.2337/dc13-2936

19. Madsen IEH, Nyberg ST, Magnusson Hanson LL, Ferrie JE, Ahola K, Alfredsson L, et al. Job strain as a risk factor for clinical depression: systematic review and meta-analysis with additional individual participant data. Psychol Med. 2017;47(8):1342-1356. https://doi.org/10.1017/S003329171600355X

20. Kivimäki M, Jokela M, Nyberg ST, Singh-Manoux A, Fransson EI, Alfredsson L, et al. Long working hours and risk of coronary heart disease and stroke: a systematic review and meta-analysis of published and unpublished data for 603,838 individuals. Lancet. 2015;386(10005):1739-1746. https://doi.org/10.1016/S0140-6736(15)60295-1

21. Kivimäki M, Virtanen M, Kawachi I, Nyberg ST, Alfredsson L, Batty GD, et al. Long working hours, socioeconomic status, and the risk of incident type 2 diabetes: a meta-analysis of published and unpublished data from 222120 individuals. Lancet Diabetes Endocrinol. 2015;3(1):27-34. https://doi.org/10.1016/S2213-8587(14)70178-0

22. Virtanen M, Jokela M, Madsen IEH, Magnusson Hanson LL, Lallukka T, Nyberg ST, et al. Long working hours and depressive symptoms: systematic review and meta-analysis of published studies and unpublished individual participant data. Scand J Work Environ Health. 2018;44(3):239-250. https://doi.org/10.5271/sjweh.3712

23. Dragano N, Siegrist J, Nyberg ST, Lunau T, Fransson EI, Alfredsson L, et al. Effort-reward imbalance at work and incident coronary heart disease: a multi-cohort study of 90,164 individuals. Epidemiology. 2017;28(4):619-626. https://doi.org/10.1097/ EDE.0000000000000666

24. Stansfeld S, Candy B. Psychosocial work environment and mental health-a meta-analytic review. Scand J Work Environ Health. 2006;32(6):443-462. https://doi.org/10.5271/sjweh.1050

25. Mikkelsen S, Coggon D, Andersen JH, Casey P, Flachs EM, Kolstad HA, et al. Are depressive disorders caused by psychosocial stressors at work? A systematic review with metaanalysis. Eur J Epidemiol. 2021;36(5):479-496. https://doi.org/10.1007/s10654-02100725-9

26. Frese M, Zapf D. Methodological issues in the study of work stress: Objective vs subjective measurement of work stress and the question of longitudinal studies. In: Cooper CL, Payne R, editors. Causes, coping and consequences of stress at work - Wiley series on studies in occupational stress. Chichester, England: John Wiley \& Sons; 1988. p. 375-411.

27. Kasl SV. Measuring job stressors and studying the health impact of the work environment: an epidemiologic commentary. J Occup Health Psychol. 1998;3(4):390-401. https://doi.org/10.1037/1076-8998.3.4.390

28. Beebee H, Hitchcock C, Menzies P, editors. The Oxford handbook of causation. Oxford, UK: Oxford University Press; 2009. Available from: https://www.oxfordhandbooks.com/view//oxfordhb/9780199279739.001.0001/oxfordhb-9780199279739-miscMatter-003. https://doi.org/10.1093/oxfordhb/9780199279739.001.0001

29. VanderWeele TJ, Hernán MA. Causal effects and natural laws: towards a conceptualization of causal counterfactuals for nonmanipulable exposures, with application to the effects of race and sex. In: Berzuini C, Dawid P, Bernardinelli L, editors. Causality: statistical perspectives and applications. Chichester, UK: Wiley; 2012. https://doi.org/10.1002/9781119945710.ch9

30. Vandenbroucke JP, Broadbent A, Pearce N. Causality and causal inference in epidemiology: the need for a pluralistic approach. Int J Epidemiol. 2016;45(6):1776-1786. https://doi.org/10.1093/ije/dyv341

31. Virtanen M, Pentti J, Vahtera J, Ferrie JE, Stansfeld SA, Helenius H, et al. Overcrowding in hospital wards as a predictor of antidepressant treatment among hospital staff. Am J Psychiatry. 2008;165(11):1482-1486. https://doi.org/10.1176/appi.ajp.2008.07121929

32. Griffin JM, Greiner BA, Stansfeld SA, Marmot M. The effect of self-reported and observed job conditions on depression and anxiety symptoms: a comparison of theoretical models. J Occup Health Psychol. 2007;12(4):334-349. https://doi.org/10.1037/10768998.12.4.334

33. Bonde JP, Munch-Hansen T, Wieclaw J, Westergaard-Nielsen N, Agerbo E. Psychosocial work environment and antidepressant medication: a prospective cohort study. BMC Public Health. 2009;9:262. https://doi.org/10.1186/1471-2458-9-262 
34. Jensen JH, Flachs EM, Török E, Rod NH, Madsen IEH, Rugulies R, et al. Work-unit social capital and incident purchase of psychotropic medications: A longitudinal cohort-study of healthcare workers. J Affect Disord. 2020;276:53-61. https://doi.org/10.1016/j. jad.2020.07.004

35. Madsen IEH, Svane-Petersen AC, Holm A, Burr H, Framke E, Melchior M, et al. Work-related violence and depressive disorder among 955,573 employees followed for 6.99 million person-years. The Danish Work Life Course Cohort study: Work-related violence and depression. J Affect Disord. 2021;288:136-144. https://doi.org/10.1016/j.jad.2021.03.065

36. Rugulies R, Framke E, Sørensen JK, Svane-Petersen AC, Alexanderson K, Bonde JP, et al. Persistent and changing job strain and risk of coronary heart disease. A population-based cohort study of 1.6 million employees in Denmark. Scand J Work Environ Health. 2020;46(4):339-349. https://doi.org/10.5271/sjweh.3891

37. Niedhammer I, Milner A, Geoffroy-Perez B, Coutrot T, LaMontagne AD, Chastang JF. Psychosocial work exposures of the job strain model and cardiovascular mortality in France: results from the STRESSJEM prospective study. Scand J Work Environ Health. 2020;46(5):542-551. https://doi.org/10.5271/sjweh.3902

38. Peters S. Although a valuable method in occupational epidemiology, job-exposure -matrices are no magic fix. Scand J Work Environ Health. 2020;46(3):231-234. https://doi.org/10.5271/sjweh.3894

39. Milner A, Krnjack L, LaMontagne AD. Psychosocial job quality and mental health among young workers: a fixed-effects regression analysis using 13 waves of annual data. Scand J Work Environ Health. 2017;43(1):50-58. https://doi.org/10.5271/sjweh.3608

40. Clark AJ, Salo P, Lange T, Jennum P, Virtanen M, Pentti J, et al. Onset of impaired sleep as a predictor of change in health-related behaviours; analysing observational data as a series of non-randomized pseudo-trials. Int J Epidemiol. 2015;44(3):1027-1037. https://doi.org/10.1093/ije/dyv063

41. Le K, Donnellan MB, Conger R. Personality development at work: workplace conditions, personality changes, and the corresponsive principle. J Pers. 2014;82(1):44-56. https://doi.org/10.1111/jopy.12032

42. Ellis L, Bonin SL. Genetics and occupation-related preferences. Evidence from adoptive and non-adoptive families. Personality and Individual Differences. 2003;35(4):929-937. https://doi.org/10.1016/S0191-8869(02)00309-4

43. Köhler CA, Evangelou E, Stubbs B, Solmi M, Veronese N, Belbasis L, et al. Mapping risk factors for depression across the lifespan: An umbrella review of evidence from meta-analyses and Mendelian randomization studies. J Psychiatr Res. 2018;103:189-207. https:// doi.org/10.1016/j.jpsychires.2018.05.020

\author{
Ida EH Madsen, PhD, Associate Editor, SJWEH \\ National Research Centre for the Working Environment, \\ Copenhagen, Denmark \\ [e-mail: ihm@nfa.dk]
}

\author{
Reiner Rugulies, PhD, Editor-in-Chief, SJWEH \\ National Research Centre for the Working Environment, \\ Copenhagen, Denmark \\ Department of Public Health and Department of \\ Psychology, University of Copenhagen, Denmark, \\ [e-mail: rer@nfa.dk]
}


